\title{
An Electron Microscope Study on the Calcification of the Exoskeleton in a Shore Crab ${ }^{* 1}$
}

\author{
Isao YANO*2
}

(Received July 10, 1975)

\begin{abstract}
The early phase of calcification of the endocuticle newly formed after molting in the shore crab, Gaetice depressus, was studied by electron microscopy. In endocuticle matrix near the outer surface of the epidermal cell in which the calcification has begun, a number of small or large granular crystallites, $2-150 \mathrm{~m} \mu$ in diameter, were found to be deposited in the fibrils. The fibrils, about $30-80 \mathrm{~m} \mu$ thick, are dispersed randomly in the ground substance. In each elliptical border of the pore canals situated between the fibrils, the small granular crystallites, $2-26 \mathrm{~m} \mu$ in diameter, are often deposited in minute spaces. With the advancement of calcification, small or large granular crystallites deposited in the fibrils begin to join with one another and gradually form the band-shaped clusters of crystallites. On the other hand, the small granular crystallites deposited in each border of the pore canals do not form any crystallite clusters even with the advancement of calcification.
\end{abstract}

Recently, several studies on the ultrastructure of the crustacean exoskeleton have been reported, ${ }^{1-4)}$ though most of them involve the decalcified tissues except only a paper ${ }^{1)}$ which concerns nondecalcified ones. A fine structural aspect of calcifying cuticles is of importance for further understanding of formation mechanism of the crustacean exoskeleton. This paper deals with the process of calcification of the endocuticle newly formed after molting in a shore crab under an electron microscope.

\section{Material and Methods}

Five males of Gaetice depressus of 5-6 $\mathrm{mm}$ in carapace length at the postmolt stage $\mathrm{B}^{* 3}, 32$ hours after molting, were used as material. Small shell-pieces removed from the cardiac region (Fig. 1) of the carapace of each specimen were fixed with cold $4 \%$ glutaraldehyde in phosphate buffer ( $\mathrm{pH} \mathrm{7.4)} \mathrm{for} 2$ hours and then postfixed with $1 \%$ osmium tetroxide for 1 hour. After embedding these pieces in Epon epoxy resin mixture, those were sectioned with a Porter-Blum microtome. Only the endocuticle portion (Fig. 2) of nondecalcified exoskeleton was examined in this study. Ultrathin sections were examined

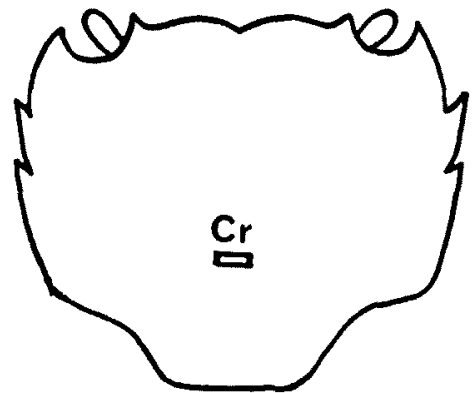

Fig. 1. Diagram of the carapace showing the part observed. The square represents the cardiac region removed. Cr: Cardiac region.

\footnotetext{
*1 国立真珠研究所菜續 No. 220

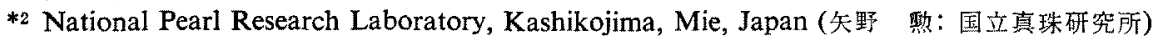

*3 stage of the molting cycle according to Drach $^{5}$
} 


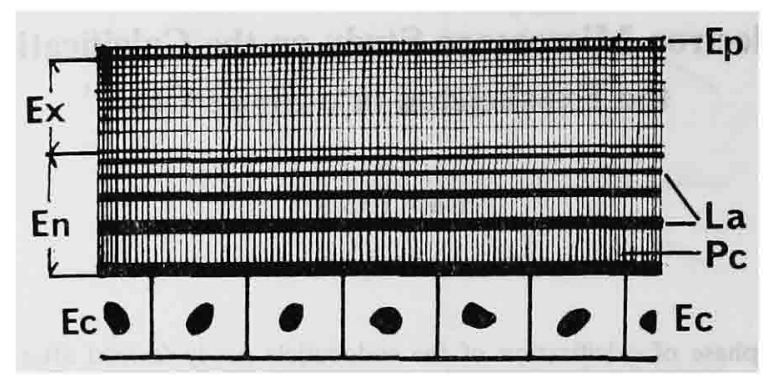

Fig. 2. Diagrammatic representation of a cross-section of the newly forming exoskeleton of the crab at the postmolt stage B. Ep: Epicuticle; Ex: Exocuticle; En: Endocuticle; La: Lamella; Pc: Pore canal; Ec: Epidermal cell.

unstained under the electron microscope of Hitachi HS-7.

\section{Observation}

Fig. 3 represents a slightly oblique section of the endocuticle newly formed in the 32 th hour following molting. This figure shows a proceeding phase of calcification in the endocuticle. The formation of mineral crystals was found to occur at a site shortly distant from the outer surface of the epidermal cell. Namely, a number of small or large granular crystallites of $2-150 \mathrm{~m} \mu$ in diameter are detected in the fibrils, about $30-80 \mathrm{~m} \mu$ thick, which are dispersed randomly in the ground substance. In each elliptical border of the pore canals placed between the fibrils, the small granular crystallites of 2-26 $\mathrm{m} \mu$ in diameter are often found to be deposited in minute spaces. In contrast, in these borders of the pore canals any fibrils are not recognizable, but the canals appear to be bounded by cytoplasmic membranes. The crystallites deposited in both of the fibrils and the borders of pore canals are regarded as crystalline $\mathrm{CaCO}_{3}$ from their characteristic contour and also from the fact that most of mineral salts in the exoskeleton of $G$. depressus are $\mathrm{CaCO}_{3}$ under chemical analysis (unpublished). TRAVIS ${ }^{1)}$ has demonstrated by X-ray diffraction that the greater part of the crystalline $\mathrm{CaCO}_{3}$ deposited in a cuticular matrix of a crayfish is calcite. With the advancement of the calcification, small or large granular crystallites deposited in the fibrils begin to join with one another and gradually become to form the band-shaped clusters of crystallites. On the other hand, the small granular crystallites deposited in the border of the pore canals do not form any crystallite clusters even with the advancement of the calcification.

\section{Discussion}

Many workers have noticed by light microscopic observation that the endocuticle begins to calcify subsequently to the formation of matrix after molting. ${ }^{6-10)}$ The present electron microscopic observation has clearly shown that in earlier calcification of the 


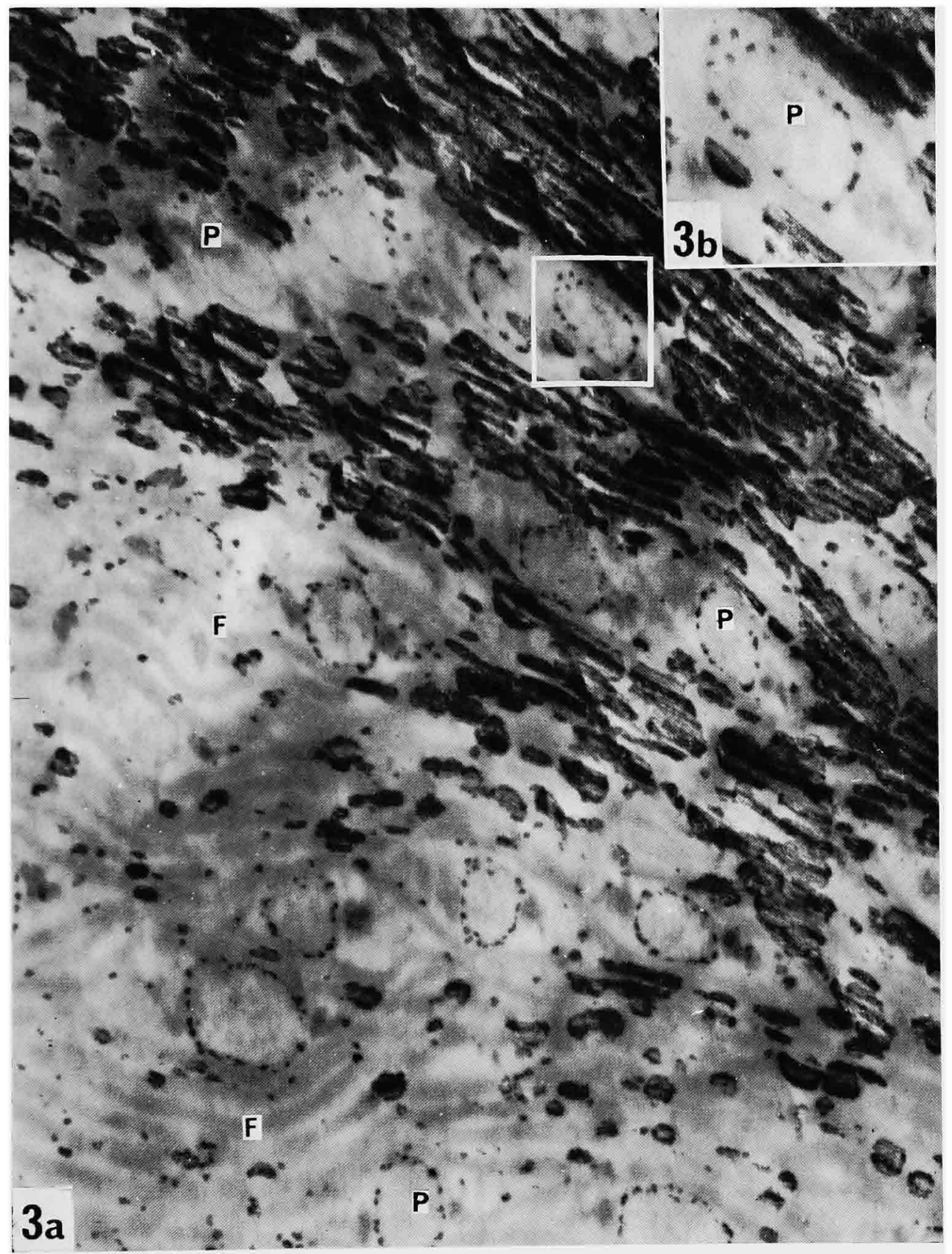

Fig. 3a. Slightly oblique section of calcifying endocuticle of the shore crab exoskeleton. Note that small or large granular crystallites scattered in both fibrils and elliptical borders of the pore canals of the matrix in which the calcification has begun. In the upper layer of the endocuticle, the band-shaped clusters of crystallites are deposited in the fibrils. P: Pore canal; F: Fibril. no stain. $\times 34700$.

Fig. 3b. Higher magnification of enclosed area in Fig. 3a. In each elliptical border of the pore canals placed between the fibrils, the small granular crystallites are often deposited in minute spaces. P: Pore canal. no stain. $\times 63100$. 
endocuticle matrix newly formed after molting, a number of mineral crystallites deposit in the fibrils. This suggests that the nucleation of crystalline $\mathrm{CaCO}_{3}$ in the endocuticle may be related to fibrils. In this respect, Travis ${ }^{1)}$ has shown in a crayfish, Orconectes virilis that calcification is initiated in the matrices by the deposition of small mineral crystallites in close association with the filaments or fibers. However, in the exoskeleton of a shore crab, $G$. depressus, any fibrils are not recognizable in the borders of the pore canals in which the small granular crystallites are deposited. At present, it is impossible to decide whether the fibrils are related or not to the nucleation of crystalline $\mathrm{CaCO}_{3}$. Further studies are necessary for understanding the nucleation of crystalline $\mathrm{CaCO}_{3}$ in the crustacean exoskeleton. With the advancement of the calcification, a number of the band-shaped clusters of crystallites are found to form in the upper layer of the endocuticle. This morphological evidence shows that growth of granular crystallites occurs even in the matrix which is distant from the outer surface of the epidermal cell. It is clear from the present observation that the innumerable pore canals, in which the cytoplasmic membranes are observed, enter transversely into the exoskeleton and the small granular crystallites are deposited in their borders. GREen and $\mathrm{NeFF}^{4}$ have shown in a fiddler crab that the microvilli of the epidermal cells enter into the pore canals of the exoskeleton. The author ${ }^{10}$ have demonstrated in a shore crab, $G$. depressus that the epidermal cells lined the exoskeleton have a close relation to the cuticle calcification under histochemical observation. These evidences imply the possibility that with further calcification of the exoskeleton, the pore canal system may play an important role in transportation of calcium salts from the epidermal cells to the matrix of the endocuticle.

\section{Acknowledgement}

The author wishes to express his hearty thanks to Professor Emeritus Shinjiro KoBAYASHI and Professor Juro YAMADA of Hokkaido University for their invaluable criticisms of the manuscript.

\section{References}

1) D. F. Travis: Ann. New York Acad. Sci., 109, 177-245 (1963).

2) K. SaikI and M. MiYaWaki: Zool. Mag., 78, 476-481 (1969).

3) A. C. Neville and B. M. LuKe; J. Insect Physiol., 17, 519-526 (1971).

4) J. P. Green and M. R. NefF: Tissue \& Cell, 4, 137-171 (1972).

5) P. Drach: Ann. Inst. Oceanog., Paris (N. S.), 19, 103-391 (1939).

6) D. F. Travis: Biol. Bull., 108, 88-112;1955).

7) D. F. Travis: ibid., 113, 451-479 (1957).

8) D. F. TRavis: Acta Histochem., 20, 193-222 (1965).

9) R. Dennell: Proc. Roy. Soc. (London), 134, 485-503 (1947).

10) I. YANO: This Bull., 38, 733-739 (1972). 